OPEN ACCESS

Edited by:

Yuji Morita,

Aichi Gakuin University, Japan

Reviewed by:

Emily E. Weinert,

Emory University, United States

Fabian Davamani Amalraj

International Medical University,

Malaysia

Sarah Rowe-Conlon,

University of North Carolina at Chapel

Hill, United States

*Correspondence:

Lin Wang

wanglin1020@jlu.edu.cn

Tiedong Wang

wangtd@jlu.edu.cn

${ }^{\dagger}$ These authors have contributed equally to this work.

Specialty section:

This article was submitted to Antimicrobials, Resistance and

Chemotherapy,

a section of the journa

Frontiers in Microbiology

Received: 23 May 2017 Accepted: 02 November 2017

Published: 15 November 2017

Citation:

Ming $D$, Wang $D$, Cao $F$, Xiang $H$, Mu D, Cao J, Li B, Zhong L, Dong $X$,

Zhong $X$, Wang $L$ and Wang $T$ (2017)

Kaempferol Inhibits the Primary

Attachment Phase of Biofilm

Formation in Staphylococcus aureus.

Front. Microbiol. 8:2263.

doi: 10.3389/fmicb.2017.02263

\section{Kaempferol Inhibits the Primary Attachment Phase of Biofilm Formation in Staphylococcus aureus}

\author{
Di Ming ${ }^{1 \dagger}$, Dacheng Wang ${ }^{1 \dagger}$, Fengjiao Cao ${ }^{2}$, Hua Xiang ${ }^{2}$, Dan $\mathrm{Mu}^{1}$, Junjie Cao', \\ Bangbang $\mathrm{Li}^{3}$, Ling Zhong ${ }^{1}$, Xiaoyun Dong ${ }^{3}$, Xiaobo Zhong ${ }^{1}$, Lin Wang ${ }^{4 *}$ and \\ Tiedong Wang ${ }^{\text {1* }}$
}

${ }^{1}$ College of Animal Science, Jilin University, Changchun, China, ${ }^{2}$ College of Animal Science and Technology, Jilin Agricultural University, Changchun, China, ${ }^{3}$ Department of Pharmacology, College of Basic Medical Science, Jilin University, Changchun, China, ${ }^{4}$ Key Laboratory of Zoonosis Research, Ministry of Education, Institute of Zoonosis, College of Veterinary Medicine, Jilin University, Changchun, China

The ability to form biofilms on surfaces makes Staphylococcus aureus the main pathogenic factor in implanted medical device infections. The aim of this study was to discover a biofilm inhibitor distinct from the antibiotics used to prevent infections resulting from S. aureus biofilms. Here, we describe kaempferol, a small molecule with anti-biofilm activity that specifically inhibited the formation of $S$. aureus biofilms. Crystal violet (CV) staining and fluorescence microscopy clearly showed that $64 \mu \mathrm{g} / \mathrm{ml}$ kaempferol inhibited biofilm formation by $80 \%$. Meanwhile, the minimum inhibitory concentration (MIC) and growth curve results indicated that kaempferol had no antibacterial activity against the tested bacterial strain. Kaempferol inhibited the primary attachment phase of biofilm formation, as determined by a fibrinogen-binding assay. Moreover, a fluorescence resonance energy transfer (FRET) assay and quantitative real-time reverse transcription polymerase chain reaction (qRT-PCR) analyses revealed that kaempferol reduced the activity of $S$. aureus sortaseA (SrtA) and the expression of adhesion-related genes. Based on these results, kaempferol provides a starting point for the development of novel anti-biofilm drugs, which may decrease the risk of bacterial drug resistance, to prevent S. aureus biofilm-related infections.

Keywords: Staphylococcus aureus, biofilm, kaempferol, inhibitor, primary, adhesion

\section{INTRODUCTION}

Staphylococcus aureus (S. aureus) is an important Gram-positive pathogen that can cause both human and animal diseases (Mistry et al., 2016). Statistically, 20-25\% of the population serve as long-term S. aureus hosts, whereas $75-80 \%$ of the population are intermittent hosts (Harmsen et al., 2010; Singhal et al., 2011). S. aureus can cause suppurative inflammation in the dermal mucous membranes and in many other tissues and organs (Lowy, 1998).

Bacterial pathogens with the ability to form biofilms, such as $S$. aureus, easily colonize the surfaces of certain indwelling medical devices (O'Gara and Humphreys, 2001; Von Eiff et al., 2002). Biofilms allow embedded bacteria to resist antimicrobial therapy (Hoyle and Costerton, 1991; Aaron et al., 2002; Parsek and Singh, 2003; Anderson and O’Toole, 2008), for 
example, by reducing contact with antimicrobial compounds (Aendekerk et al., 2005; Bjarnsholt et al., 2005) or reducing metabolic activity, which lowers the sensitivity to multiple antibiotics (Anderson and O'Toole, 2008). Consequently, the control of biofilm-forming $S$. aureus is very difficult (Costerton et al., 1999; Mah and O'Toole, 2001). The efficacy of single antibiotics against $S$. aureus biofilms in clinical practice is poor (Rogers et al., 2010), and as a result, new therapeutic strategies and molecular data on potential means of disturbing biofilm development are in great demand (Romling and Balsalobre, 2012).

The development of a bacterial biofilm can be divided into the following phases: initial adhesion, proliferation, maturation and diffusion (Otto, 2008; Boles and Horswill, 2011). Three principle strategies target the different stages of biofilm development: attachment inhibition, biofilm architecture disruption and signal transduction interference (Chung and Toh, 2014). Various inhibitors such as plantderived natural compounds or synthesized small molecules (Brackman and Coenye, 2015; Mogosanu et al., 2015), enzymes targeting the matrix (Itoh et al., 2005), an enzyme from an S. aureus bacteriophage that degrades the cell wall (Kelly et al., 2012), nanoparticles and silver ions (Jia et al., 2017), polysaccharides and synthetic peptides with anti-biofilm activity (Rendueles et al., 2013; Pletzer and Hancock, 2016) have been discovered.

Plant secondary metabolites are main sources of antimicrobial agents and other pharmaceuticals (Li and Vederas, 2009; Lee et al., 2016). Some biofilm inhibitors derived from plants have been found to exhibit activity against $S$. aureus biofilms, including magnolol (Wang et al., 2011), ellagic acid (Quave et al., 2012), tannic acid (Payne et al., 2013), quercetin (Lee et al., 2013), ginkgolic acids (Lee et al., 2014), eugenol (Yadav et al., 2015), and flavonoids (Cho et al., 2015).

Despite their great potential for treating biofilm-related infections, the mechanism of action of these agents remains unclear. Our research currently aims to discover small molecule compounds that specifically act on the key virulence factors in bacteria, such as listeriolysin $\mathrm{O}$ of Listeria monocytogenes and $\alpha$-hemolysin (Hla) and SrtA of S. aureus (Qiu et al., 2012; Wang J. et al., 2015; Wang L. et al., 2015). The ability to form biofilms is now believed to be an important virulence characteristic for some Staphylococcus bacteria. Therefore, we screened S. aureus biofilm inhibitors from 200 natural compounds preserved in our laboratory and found that kaempferol (Figure 1A) exhibited good anti-biofilm activity.

Kaempferol is a typical flavonol with many biological and pharmacological activities, including antitumor, antiinflammatory, and antioxidative effects (Ross and Kasum, 2002). In addition, kaempferol is known to inhibit the activity of S. aureus PriA helicase (SaPriA) and the activity of bacterial efflux pumps, thereby blocking the growth and survival of antibioticresistant $S$. aureus and increasing antimicrobial effectiveness (Brown et al., 2015; Huang et al., 2015). In our study, we tested the capacity of kaempferol to inhibit S. aureus ATCC ${ }^{\circledR} 29213^{\mathrm{TM}}$ biofilm formation and explored the specific stages and potential molecular mechanisms of this activity in depth.

\section{MATERIALS AND METHODS}

\section{Strains and Growth Conditions}

The S. aureus strain ATCC ${ }^{\circledR} 29213^{\mathrm{TM}}$ (National Center For Medical Culture Collections) was used in this study for its high ability to form biofilms in vitro (Abouelhassan et al., 2014). The $\Delta$ SrtA strain was constructed using a method described previously (Chen et al., 2014). The SrtA $\Delta$ N59 protein was constructed in the previous study by our team (Wang L. et al., 2015). The fluorescent peptide Dabcyl-QALPETGEE-Edans was synthesized by GL Biochem (Shanghai, China). The S. aureus ATCC $^{\circledR} 29213^{\mathrm{TM}}$ and $\triangle$ SrtA strains were cultured in brain-heart infusion (BHI) solution (Oxoid, Basingstoke, UK) supplemented with $0.5 \%$ glucose and $3 \% \mathrm{NaCl}$ at $37^{\circ} \mathrm{C}$ with shaking at $220 \mathrm{rpm}$.

\section{Antimicrobial Agents}

Kaempferol was purchased from the Chengdu Ruifensi Biotech Company (Chengdu, China) and dissolved in dimethyl sulfoxide (DMSO) (Changchun Baotaike Biotech Company, China) to a storage concentration of $100 \mathrm{mg} / \mathrm{ml}$.

\section{Biofilm Inhibitor Screening}

The S. aureus ATCC ${ }^{\circledR} 29213^{\mathrm{TM}}$ strain was cultured overnight and then diluted 1:100 in sterile BHI broth supplemented with $0.5 \%$ glucose and $3 \% \mathrm{NaCl}$. Then, $200 \mu \mathrm{l}$ of diluted bacteria was placed in a polystyrene Costar 96-well plate (Tiangen, Changchun Baotaike Biotech Company, China) coated with plasma (20\% rabbit freeze-dried plasma, incubated overnight at $4^{\circ} \mathrm{C}$ ). Compounds were added to the assay plates at a final concentration of $512 \mu \mathrm{g} / \mathrm{ml}$, and the plate was incubated at $37^{\circ} \mathrm{C}$ for $12 \mathrm{~h}$ without shaking. Then, the supernatant was completely removed. After rinsing in phosphate buffered saline (PBS), the biofilms were stained with $12.5 \mathrm{~g} / \mathrm{l}$ crystal violet $(\mathrm{CV})$ for $10 \mathrm{~min}$, washed again with PBS and dried. Images were obtained using an AMT $2 \mathrm{k}$ charge-coupled device (CCD) camera. Finally, $0.2 \mathrm{ml}$ of ethanol (95\%) was added to the CV-stained wells, which were then incubated for $30 \mathrm{~min}$ to quantify biofilm growth, and $100 \mu \mathrm{l}$ of each final dissolved CV solution was transferred into new 96-well plates and measured at an OD of $595 \mathrm{~nm}$ using a microplate reader (Infinite ${ }^{\circledR}$ F500, Tecan, Shanghai, China). Each data point consisted of three independent samples. The compounds that showed $90 \%$ inhibition compared with the negative control (no compound added) were selected as validated hits.

\section{MIC and Growth Curves}

The minimum inhibitory concentration (MIC) of kaempferol were determined in accordance with the Clinical and Laboratory Standards Institute (CLSI) Approved Standard M7-A8, (CLSI, Wayne, PA, 2009, pp. 19-91). To obtain growth curves, S. aureus was cultured overnight and diluted 1:100 into sterile BHI (supplemented with $0.5 \%$ glucose and $3 \% \mathrm{NaCl}$ ) broth with or without kaempferol at different concentrations. The absorbance at $600 \mathrm{~nm}$ was measured at different time intervals.

\section{Fluorescence Microscopy}

Sytox green was obtained from Invitrogen-Molecular Probes (Oregon). After treatment with 128, 64, and $32 \mu \mathrm{g} / \mathrm{ml}$ kaempferol 
<smiles>O=c1c(O)c(-c2ccc(O)cc2)oc2cc(O)cc(O)c12</smiles>

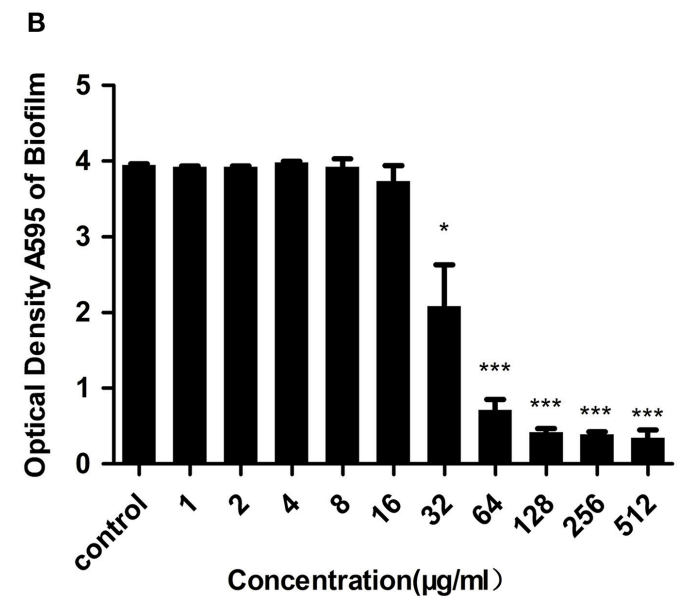

D

C
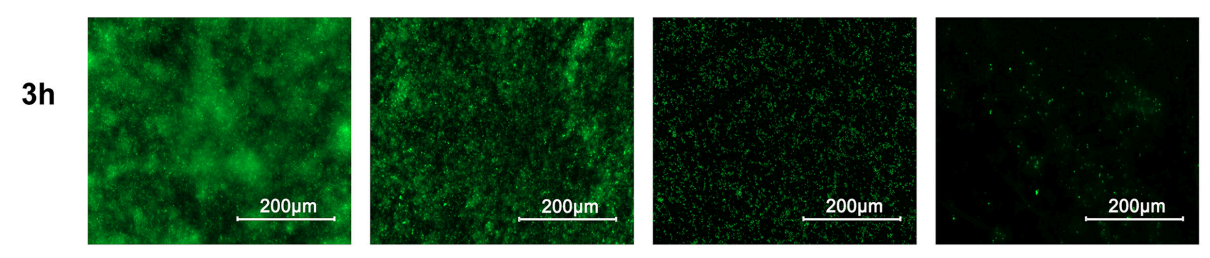

$6 h$
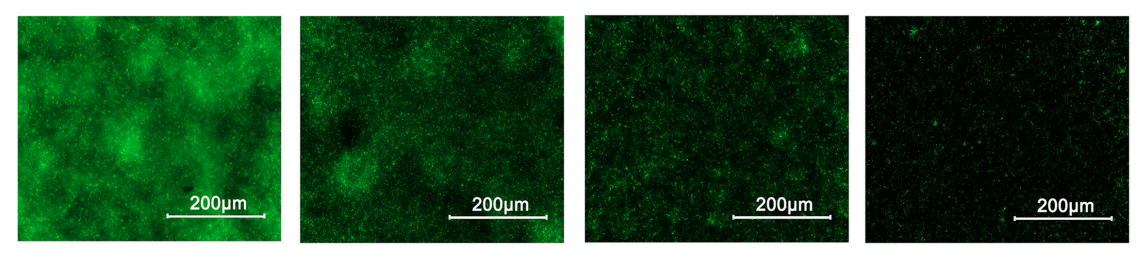

$12 \mathrm{~h}$

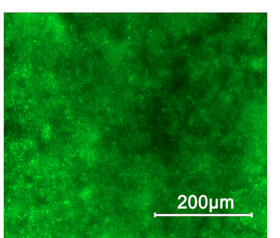

Control

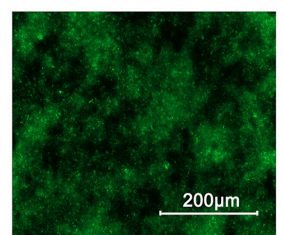

$32 \mu \mathrm{g} / \mathrm{ml}$

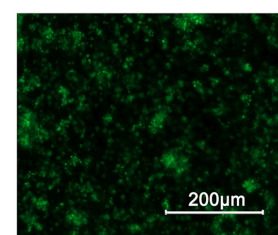

$64 \mu \mathrm{g} / \mathrm{ml}$

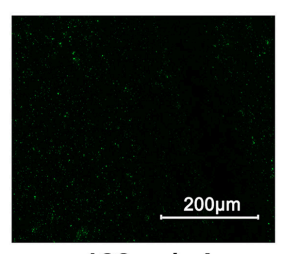

$128 \mu \mathrm{g} / \mathrm{ml}$

FIGURE 1 | Anti-biofilm and antibacterial activities of kaempferol against S. aureus ATCC ${ }^{\circledR} 29213^{\text {TM }}$. (A) Chemical structure of kaempferol. (B) S. aureus was incubated with various concentrations of kaempferol for $12 \mathrm{~h}$. CV was used to stain the biofilms. The bound CV was released from the stained cells with $95 \%$ ethanol, and the OD595 was measured. Data are represented as the mean \pm standard deviation. ${ }^{\star} P<0.05$, and ${ }^{\star \star \star} P<0.001$ compared to the control. (C) Fluorescence microscopy. Scale bars represent $200 \mu \mathrm{m}$. (D) Growth curve of S. aureus ATCC ${ }^{\circledR} 29213^{\text {TM }}$ with or without kaempferol. Kaempferol at 64,128 , and $256 \mu \mathrm{g} / \mathrm{ml}$ had no effect on bacterial growth compared with that of the control group.

for 3, 6 and $12 \mathrm{~h}$, the biofilms produced by each group were washed with PBS. To permeabilize the bacterial membranes, the cell growth substrates were soaked in $0.1 \%$ (vol/vol)
Triton X-100 (VWR) in PBS (PBST) for $15 \mathrm{~min}$. The cells were labeled by replacing the PBST with $0.5 \mu \mathrm{M}$ Sytox green nucleic acid stain in PBST for $30 \mathrm{~min}$. The cells were then washed 
with PBS to remove the excess stains. Afterwards, fluorescent images were obtained using a fluorescence microscope (Leica DMRX).

\section{Fibrinogen-Binding Assay}

The S. aureus ATCC ${ }^{\circledR} 29213^{\mathrm{TM}}$ strain was cultured overnight and then diluted 1:100 in sterile BHI (supplemented with $0.5 \%$ glucose and $3 \% \mathrm{NaCl}$ ) broth containing different concentrations of kaempferol and cultured with shaking at $37^{\circ} \mathrm{C}$. All cells were collected by centrifugation $(5,000 \times \mathrm{g}$ for $5 \mathrm{~min})$ when the OD600 reached 0.5. The cells were suspended in PBS to obtain an OD600 of 1.0. The resuspended cells were placed to polystyrene Costar 96-well plates coated with fibrinogen (incubated overnight with $20 \mu \mathrm{g} / \mathrm{ml}$ bovine fibrinogen at $4^{\circ} \mathrm{C}$ ) and incubated for $1 \mathrm{~h}$ at $37^{\circ} \mathrm{C}$. The supernatant was removed, and the cells were washed with PBS and fixed with 25\% (v/v) formaldehyde. After $30 \mathrm{~min}$, the adherent bacteria were washed again with PBS and stained with $12.5 \mathrm{~g} / \mathrm{l} \mathrm{CV}$ for $10 \mathrm{~min}$. The wells were then washed with PBS and dried. Subsequently, different samples were measured at $595 \mathrm{~nm}$. The percentage of the tested group compared to the control group was used to report results. To ensure reproducibility, each experiment was repeated at least three times.

\section{Inhibition of Sortase A Activity}

The influence of kaempferol on SrtA was examined by a fluorescence resonance energy transfer (FRET) method (TonThat et al., 1999; Mazmanian et al., 2002). Sortase A (SrtA), an enzyme that anchors surface proteins to the cell wall of Gram-positive bacteria, cleaves sorting signals between the threonine (T) and glycine $(\mathrm{G})$ of the LPXTG motif (Ton-That et al., 1999). During SrtA catalysis, the change in fluorescence was monitored using the fluorescent peptide substrate DabcylQALPETGEE-Edans of SrtA. The inhibitory effect of kaempferol on the activity of SrtA was measured based on the fluorescence changes. The sortase A (SrtA) activity inhibition assay was conducted according to a method described previously ( $\mathrm{Bi}$ et al., 2016). The experiment was performed in black 96-well plates. The reaction consisted of $4 \mu \mathrm{M} \mathrm{SrtA}_{\triangle N 59}$ protein, $10 \mu \mathrm{M}$ peptide substrate and the assay buffer $(150 \mathrm{mM} \mathrm{NaCl}, 5 \mathrm{mM}$ $\mathrm{CaCl}_{2}, 0.1 \%$ Triton $\mathrm{X}-100$ and $50 \mathrm{mM}$ Tris- $\left.\mathrm{HCl}, \mathrm{pH} 7.5\right)$ in a final volume of $300 \mu \mathrm{l}$. The $\operatorname{SrtA}_{\Delta N 59}$ protein and different concentrations of kaempferol were added to the plate and incubated at $37^{\circ} \mathrm{C}$ for $1 \mathrm{~h}$. Then, the peptide substrate was added, and the reaction continued for another $1 \mathrm{~h}$ at $37^{\circ} \mathrm{C}$. The change in fluorescence intensity was detected using a microplate reader (Infinite ${ }^{\circledR}$ F500, Tecan, Shanghai, China) with $495 \mathrm{~nm}$ as the emission wavelength and $350 \mathrm{~nm}$ as the excitation wavelength. To ensure the reproducibility of this assay, each reaction was repeated three times.

\section{Transmission Electron Microscopy}

Transmission electron microscopy (TEM) was performed using a JEM-2100 transmission microscope (JEOL, Tokyo, Japan). Biofilm samples were prepared according to the method described above. For the proteinase $\mathrm{K}$ group, proteinase $\mathrm{K}$ $(2 \mu \mathrm{g} / \mathrm{ml})$ was added to the pre-established biofilms and incubated for $2 \mathrm{~h}$ at $37^{\circ} \mathrm{C}$. Samples prepared for TEM imaging were spotted onto formvar-coated copper grids, incubated for 5 min, washed with sterile distilled $\mathrm{H}_{2} \mathrm{O}$, and negatively stained with $2 \%$ uranyl acetate for 60 s (Chu et al., 2016).

\section{Confocal Microscopy}

The confocal microscopy experiment was performed using confocal laser-scanning microscopy (Olympus, Shanghai, China). Syto 63 and fluorescein isothiocyanate (FITC) were purchased from Invitrogen Molecular Probes (Oregon). The biofilms were cultured according to the above method on glass cover slides with or without kaempferol $(64 \mu \mathrm{g} / \mathrm{ml})$. The biofilms produced by each group were washed with PBS after $12 \mathrm{~h}$. Syto $63(100 \mu \mathrm{M})$ was added to each well, and the plate was incubated with shaking for $5 \mathrm{~min}$. FITC $(0.001 \%)$ was then added, and the plate was incubated for another $30 \mathrm{~min}$ without shaking. The cells were washed with PBS to remove excess stain. Confocal microscopy images were obtained from NIS-Elements $\mathrm{C}$ version 3.2 (Nikon Eclipse).

\section{RNA Isolation}

For quantitative real-time reverse transcription polymerase chain reaction (qRT-PCR) experiments, RNA from $S$. aureus cells was isolated using the following procedure. The $S$. aureus ATCC $^{\circledR} 29213^{\mathrm{TM}}$ strain was cultured overnight and diluted 1:100 into sterile $\mathrm{BHI}$ broth supplemented with $0.5 \%$ glucose and $3 \%$ $\mathrm{NaCl}$. After culturing at $37^{\circ} \mathrm{C}$ for $3 \mathrm{~h}$ with shaking at $220 \mathrm{rpm}$, kaempferol was added to a concentration of $64 \mu \mathrm{g} / \mathrm{ml}$ - at which it showed significant anti-biofilm activity-and the culture was incubated again for $5 \mathrm{~h}$. Subsequently, RNA was isolated using the TRIzol (Tiangen, Changchun Baotaike Biotech Company, China) RNA extraction method. The concentration of RNA was assessed using a NanoVue Plus (Biochrom Ltd., Cambridge, $\mathrm{UK})$.

\section{qRT-PCR}

qRT-PCR was used to assess the transcription levels of adhesionrelated genes $(f n b A, f n b B, c l f A, c l f B, s a r A)$ in $S$. aureus ATCC $^{\circledR}$ $29213^{\mathrm{TM}}$. Gene-specific primers (listed in Table 1) were used for these genes, and appropriate primers were used for $16 \mathrm{~S}$ rRNA as a housekeeping control to normalize the expression of genes of interest. The isolated RNAs were reverse-transcribed into cDNA using the TransScript ${ }^{\circledR}$ All-in-One First-Strand cDNA Synthesis SuperMix (Quanshijin, Changchun Weierkete Biotech Company, China). Then, qRT-PCR was performed using the TransStart Top Green qPCR SuperMix (Quanshijin, Changchun Weierkete Biotech Company, China) under the following conditions: initial denaturation at $95^{\circ} \mathrm{C}$ for $10 \mathrm{~min}$ followed by 40 cycles of $95^{\circ} \mathrm{C}$ for $15 \mathrm{~s}, 60^{\circ} \mathrm{C}$ for $10 \mathrm{~s}$ and $72^{\circ} \mathrm{C}$ for $10 \mathrm{~s}$. As a negative control, qRT-PCR was performed without cDNA. The experiments were performed three times in parallel, and the data were analyzed using a previously described relative quantitative $\left(2^{-\Delta \Delta \mathrm{Ct}}\right)$ method (Livak and Schmittgen, 2001). 
TABLE 1 | Oligonucleotide primers used in this study.

\begin{tabular}{ll}
\hline Primer name & Oligonucleotide $\left(\mathbf{5}^{\prime} \mathbf{-} \mathbf{3}^{\prime} \mathbf{)}\right.$ \\
\hline $16 S$ rRNA- $F$ & GCTGCCCTTGTATTGTC \\
$16 S$ rRNA- $R$ & AGATGTTGGTTAAGTCC \\
$f n b A-F$ & GACCCGCTTCACTAT \\
$f n b A-R$ & ACACCGCTTGACATT \\
$f n b B-F$ & AATAAGGATAGTATGGGTAG \\
$f n b B-R$ & CACAAGTAATGGTCGGT \\
ClfA- $F$ & TTGATTGGCGATACG \\
ClfA- $R$ & TGACCCTGAAAATGTA \\
ClfB- $F$ & ACGAATGGCGATGTT \\
ClfB- $R$ & CACTACGACGACCATA \\
sarA- $F$ & ATGATTGCTATGAGTT \\
sarA- $R$ & TGTTCGCTGATGTATG \\
\hline
\end{tabular}

\section{Statistical Analysis}

Statistical analyses were conducted using Student's $t$-test with SPSS 13.0 software. The data were expressed as the mean \pm standard deviation. Values of $p<0.05$ were considered statistically significant.

\section{RESULTS}

\section{Kaempferol Inhibits the Formation of S. aureus Biofilms without Affecting the Growth of Planktonic Bacteria}

According to the screening assay, kaempferol at $512 \mu \mathrm{g} / \mathrm{ml}$ showed $90 \%$ inhibition on the biofilm formation representing that it had obvious anti-biofilm activity. To detect the influence of different concentrations of kaempferol on S. aureus biofilms, S. aureus was co-cultured with kaempferol $(1-512 \mu \mathrm{g} / \mathrm{ml})$ using the microdilution method, which was similar to the MIC assay for planktonic cells in 96-well plates coated with $20 \%$ rabbit freeze-dried plasma at $37^{\circ} \mathrm{C}$ for $12 \mathrm{~h}$ without shaking. After $12 \mathrm{~h}$, we stained the biofilm with crystal violet and measured the absorbance at $595 \mathrm{~nm}$. We observed that kaempferol was effective at lower concentrations, and it could inhibit biofilm formation by $80 \%$ at $64 \mu \mathrm{g} / \mathrm{ml}$ (Figure $\mathbf{1 B}$ ).

The nucleic acid dye Sytox Green is a fluorescent indicator that can efficiently label the entire cytoplasm (Hochbaum et al., 2011). Therefore, the effect of kaempferol on biofilms was observed by the fluorescence microscopy. Fluorescent images indicated that biofilm of the control group increased gradually with time, whereas kaempferol dose-dependently inhibited the biofilm formation (Figure 1C).

To test whether the effect of kaempferol on biofilms was dependent on the inhibition of the growth of planktonic bacteria, MIC of kaempferol was determined by MIC experiment. The results showed that the MIC of kaempferol on $S$. aureus was greater than $1,024 \mu \mathrm{g} / \mathrm{ml}$. In addition, the results of the growth curve were consistent with the MIC results: bacteria treated with different concentrations of kaempferol $(64-256 \mu \mathrm{g} / \mathrm{ml})$ showed the same growth trend as the control group (Figure 1D). These results confirmed that kaempferol did not affect the growth of S. aureus at concentrations of $64-256 \mu \mathrm{g} / \mathrm{ml}$ but could significantly inhibit the formation of $S$. aureus biofilms.

\section{Kaempferol Specifically Inhibits the Initial Attachment Phase of $S$. aureus Biofilm Formation}

The development of bacterial biofilm can be divided into the following three phases, which involve specific molecular factors: attachment, maturation, and detachment (Otto, 2013). To explore which phases of biofilm development kaempferol influenced, we added kaempferol $(64 \mu \mathrm{g} / \mathrm{ml})$ at different time points during biofilm formation and measured the effects after a total of $20 \mathrm{~h}$ of incubation. There was no inhibitor in the control group. As shown in Figure 2A, compared to the control group, kaempferol significantly inhibited the formation of biofilms only when added immediately after inoculation $(0 \mathrm{~h})$. After bacteria were incubated for $1,2,3,4,8$, and $12 \mathrm{~h}$, the addition of kaempferol had no effect and the biofilms were completely resistant to kaempferol. These results demonstrated that kaempferol specifically inhibited the attachment phase of biofilm formation.

The above results showed that kaempferol only affected the attachment phase of biofilm formation, and this phase was primarily mediated by the binding of $S$. aureus surface-anchored proteins and host matrix proteins (Otto, 2013). Fibrinogen, as a plasma protein, can be used as a substrate for staphylococcal adhesion (Patti et al., 1994). To examine the influence of kaempferol on S. aureus adhesion, we therefore employed a fibrinogen-bing assay in which cell adhesion to fibrinogen-coated plates was stained with crystal violet and quantified by measuring the absorbance at $595 \mathrm{~nm}$. The relative \% adhesion was reduced after treatment with kaempferol at $32 \mu \mathrm{g} / \mathrm{ml}$ compared to the control group. When treating with $64 \mu \mathrm{g} / \mathrm{ml}$ of kaempferol, the relative \% adhesion decreased by approximately $75 \%$ (Figure 2B). These results indicated that kaempferol inhibited the formation of biofilm by reducing S. aureus adhesion.

\section{Kaempferol Prevents the Formation of S. aureus Biofilms by Inhibiting the Activity of Sortase A}

S. aureus surface proteins include clumping factors (ClfA and $\mathrm{ClfB})$, which are essential for the adhesion of $S$. aureus to fibrinogen (Bi et al., 2016). These proteins are mainly anchored by sortase $\mathrm{A}$ to the cell wall and play significant roles in the formation of biofilms (Cascioferro et al., 2014). Thus, we cultured the biofilm of a sortase A-null mutant of $S$. aureus $(\Delta$ SrtA). The result shown in Figure 3A proved that the $\Delta$ SrtA strain had no ability to form biofilms, further indicating that SrtA-mediated surface proteins were essential for this strain (S. aureus ATCC ${ }^{\circledR} 29213^{\mathrm{TM}}$ ) to form biofilms under these conditions. Based on this result, to test the effect of kaempferol on the activity of SrtA, we performed a FRET (Ton-That et al., 1999; Mazmanian et al., 2002) assay in vitro in which a fluorescent peptide substrate Dabcyl-QALPETGEE-Edans of SrtA was used to monitor the fluorescence changes during SrtA catalysis. The result showed that SrtA activity was blocked 

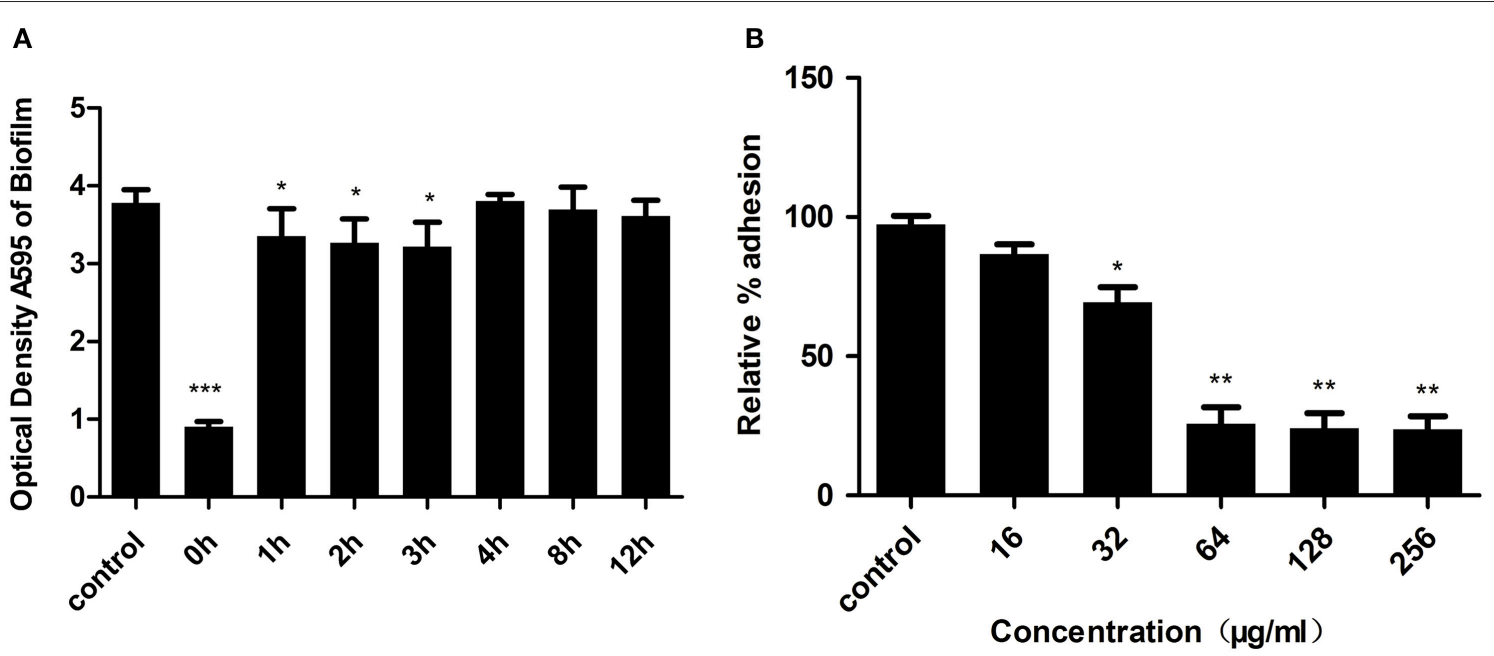

FIGURE 2 | (A) Kaempferol specifically inhibited the attachment of phase biofilm formation. Kaempferol was added at various time points during biofilm formation, and the effects were measured after a total of $20 \mathrm{~h}$ of incubation. CV was used to stain the biofilms. The bound CV was released from the stained cells with $95 \%$ ethanol, and the OD595 was measured. Data are represented as the mean \pm standard deviation. ${ }^{\star} P<0.05$, and ${ }^{\star \star \star} P<0.001$ compared to the control. (B) Relative $\%$ adhesion of $\mathrm{S}$. aureus to fibrinogen. Bacteria treated with kaempferol were cultured in 96 -well plates coated with $20 \mu \mathrm{g} / \mathrm{ml}$ fibrinogen at $37^{\circ} \mathrm{C}$ for $1 \mathrm{~h}$. The OD595 was measured as described above. The relative \% adhesion was calculated. ${ }^{\star \star} P<0.05$, and ${ }^{\star \star} P<0.01$.

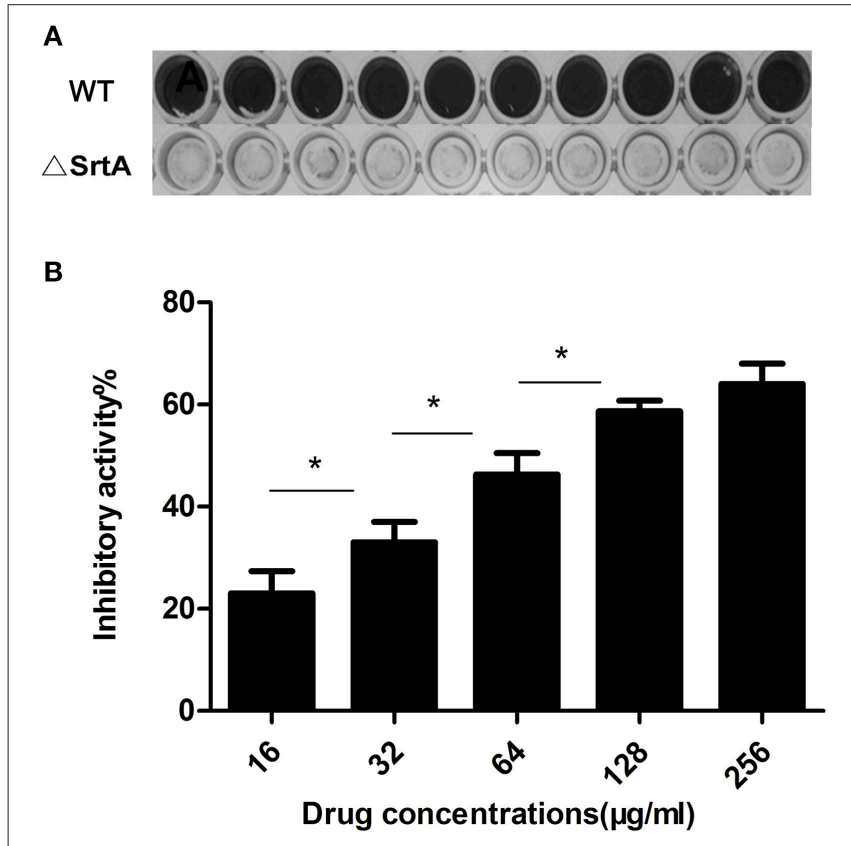

FIGURE 3 | (A) Wild-type and $\triangle$ SrtA S. aureus biofilms. (B) Inhibitory effect of kaempferol on the activity of $S$. aureus SitA in Vitro. ${ }^{*} P<0.05$.

by $47 \%$ (Figure 3B) after treatment with $64 \mu \mathrm{g} / \mathrm{ml}$ kaempferol, suggesting that kaempferol weakened the adhesion of $S$. aureus by blocking the activity of SrtA, resulting in the inhibition of biofilm formation.

In addition, under a transmission electron microscope (TEM), we observed many fibrous protrusions around the wildtype strain (Figures $\mathbf{4 A , E}$ ). Biofilms treated with proteinase $\mathrm{K}$ were dispersed (data not shown) and the fibrous protrusions disappeared (Figures 4B,F). As shown in Figures 4C,G, the surface of $\Delta$ SrtA strain was also smooth. A significant reduction of fibrous protrusions on the surface of bacteria was observed after treatment with $64 \mu \mathrm{g} / \mathrm{ml}$ kaempferol (Figures 4D,H). Moreover, we chose two fluorescent dyes, Syto63 and FITC. The intracellular DNA were stained red with Syto63 dye and the extracellular proteins were stained green with FITC dye. Under confocal laser microscopy, there was obvious green fluorescence around the wild-type strain (Figure 4I) and the green fluorescence decreased after treatment with kaempferol at $64 \mu \mathrm{g} / \mathrm{ml}$ (Figure 4J).

Based on these data, we inferred that kaempferol reduced the anchoring of surface proteins by inhibiting the activity of SrtA, which led to biofilm formation inhibited.

\section{Kaempferol Modulates the Expression of S. aureus Adhesion-Related Genes}

According to the preceding conclusions, kaempferol blocked the activity of SrtA by only $47 \%$ at $64 \mu \mathrm{g} / \mathrm{ml}$, whereas inhibited the biofilm formation of $S$. aureus by $80 \%$ at this concentration. So, there may be other targets for kaempferol to affect the biofilm formation. Above results illustrated that kaempferol only acted on the adhesion stage of biofilm formation. To further investigate the molecular mechanism of adhesion inhibition, qRT-PCR was conducted to detect the transcription level of several adhesionrelated genes. As shown in Figure 5, the expression of several genes was altered. The genes $\operatorname{clf} A$ and $c l f B$, which encode Clumping factor A (ClfA) and ClfB were repressed by 45 and $88 \%$. In addition, kaempferol also down-regulated $f n b A$ and $f n b B$ which encode Fibronectin-binding proteins (FnbpA and FnbpB). The inhibition rates were 56 and $72 \%$. The global regulatory 


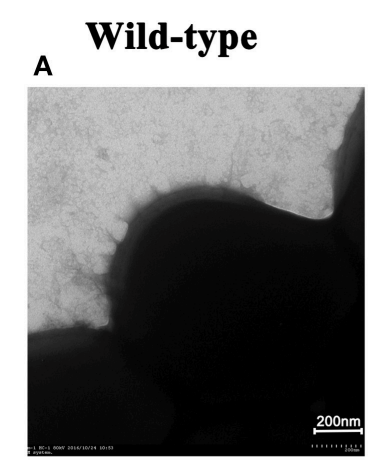

E

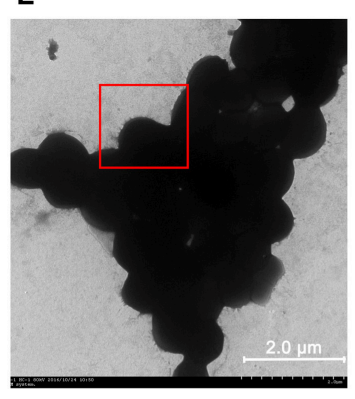

I
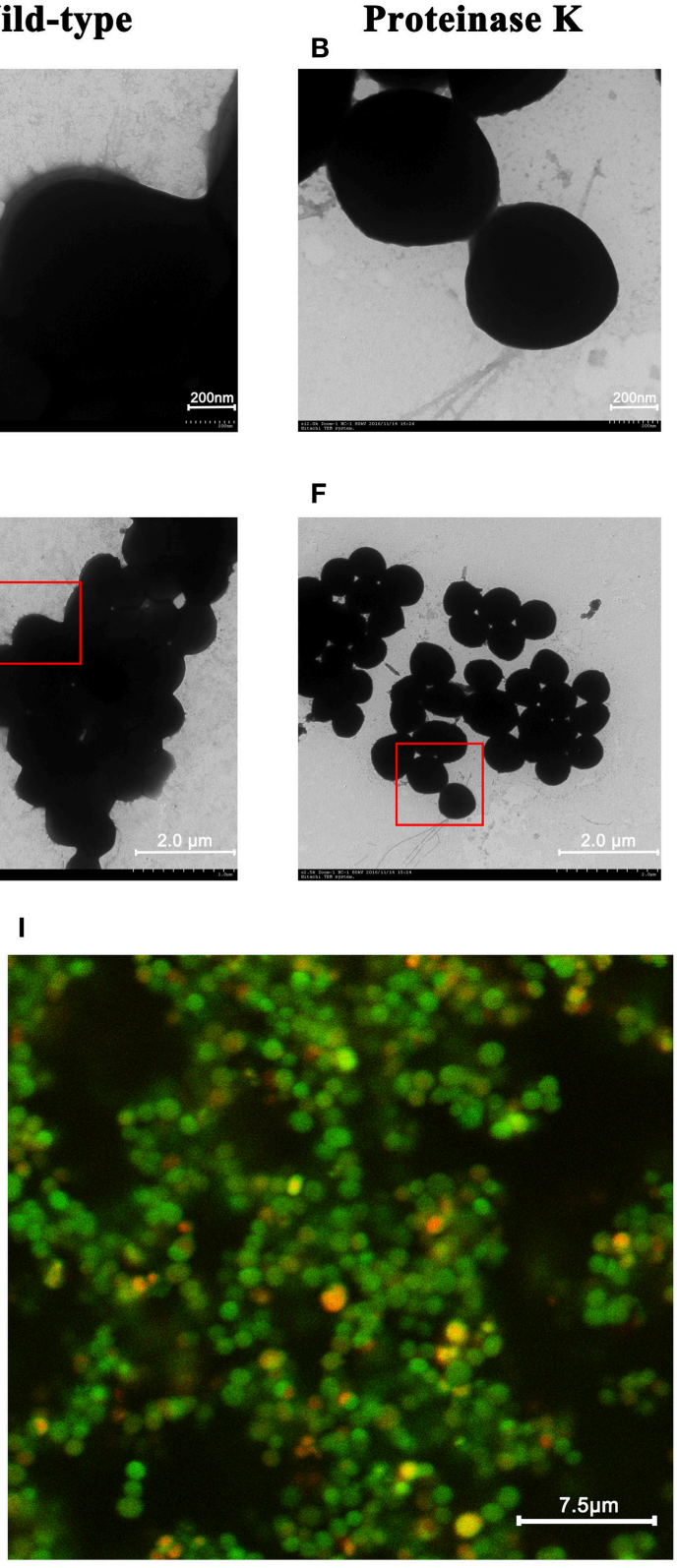

F

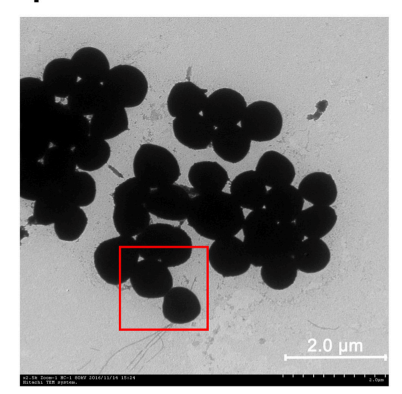

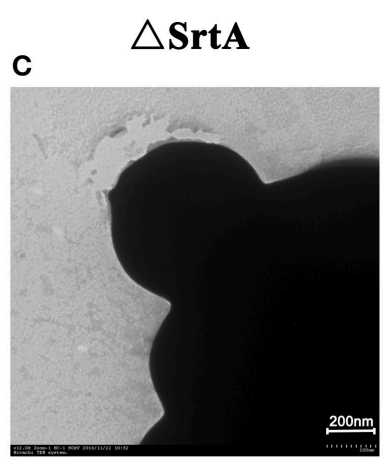

$\underset{D}{\text { Kaempferol }}(64 \mu \mathrm{g} / \mathrm{ml})$

G
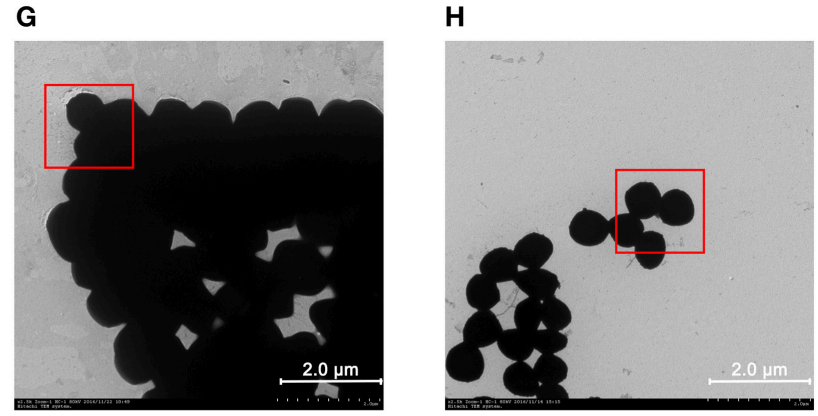

$\mathbf{J}$

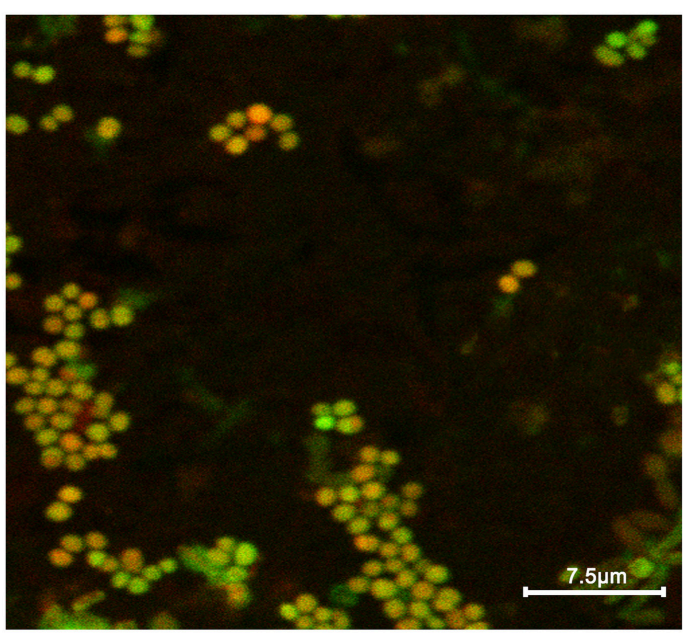

FIGURE 4 | TEM. (A,E) Wild-type group. (B,F) Proteinase K group. (C,G) $\Delta$ SrtA group. (D,H) Kaempferol $64 \mu \mathrm{g} / \mathrm{ml}$ group. Confocal microscopy images of S. aureus biofilms grown with or without kaempferol. (I) Wild-type group. (J) Kaempferol $64 \mu \mathrm{g} / \mathrm{ml}$ group.

gene sarA was studied here as well and it was inhibited by $77 \%$. The expression level of the $16 \mathrm{~S}$ rRNA gene served as the internal control. These results suggested that kaempferol down-regulated the expression of adhesion-related genes, which was responsible to explain its inhibitory effect on the biofilm formation.

\section{DISCUSSION}

The increasing rate of antibiotic resistance makes $S$. aureus a major cause of hospital infections. In $S$. aureus, biofilm formation is a mechanism of antibiotic resistance, further limiting the efficacy of antibiotics by creating a physical barrier and due to differences in metabolism (Hochbaum et al., 2011). The appearance of multidrug-resistant $S$. aureus makes it urgent to find a more effective way to treat biofilm-associated infections.

During the initial adhesion phase, cell wall-anchored (CWA) proteins of $S$. aureus play an important role in adhesion to biotic surfaces surrounded by host tissues and to abiotic surfaces coated with plasma proteins. Bacterial surface proteins that bind human matrix proteins are collectively known as microbial surface components recognizing adhesive matrix molecules 


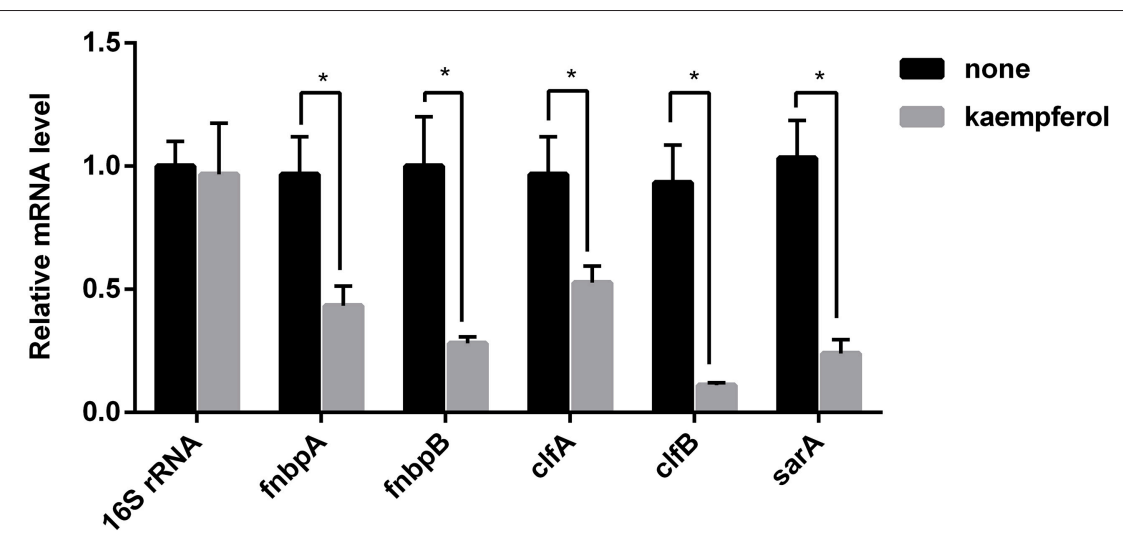

FIGURE 5 | Transcription profiles of S. aureus cells treated with or without kaempferol. S. aureus ATCC ${ }^{\circledR} 29213^{\text {TM }}$ was cultivated to an A600 of 1 and incubated with or without kaempferol $(64 \mu \mathrm{g} / \mathrm{ml})$ for $5 \mathrm{~h}$ with shaking at $220 \mathrm{rpm}$. Transcriptional profiles were measured by qRT-PCR. The expression level of $16 \mathrm{~S}$ rRNA was used to normalize the expression of the genes of interest. The experiment was performed in triplicate ( 3 qRT-PCR replicates were performed per gene). ${ }^{*}<0.05$ vs. non-treated controls (none).

(MSCRAMMs) (Otto, 2014). Some MSCRAMMs are known to be related to the early stages of biofilm formation, such as FnBPA, FnBPB (Massey et al., 2002; Foster et al., 2014), and the clumping factors ClfA (McDevitt et al., 1997) and ClfB (Ní Eidhin et al., 1998). Most MSCRAMMs in S. aureus have a common cell walltargeting motif (LPXTG) and are targeted to bacterial surfaces via sortase A (SrtA), which catalyzes the covalent attachment of these proteins to the penta-glycine cross-linker component of the peptidoglycan (Mazmanian et al., 1999) and plays significant roles in bacterial adhesion (Cascioferro et al., 2014; Zapotoczna et al., 2015).

Our results showed that kaempferol reduced the adhesion of bacteria to fibrinogen, which is the first step in the formation of S. aureus biofilms (Götz, 2002). One possible mechanism of action is that kaempferol destroys the activity of SrtA and thus hinders the anchoring of surface proteins. FRET (TonThat et al., 1999; Mazmanian et al., 2002) was used to examine the inhibitory activity of kaempferol against SrtA in vitro. An enzyme activity assay indicated that the activity of SrtA was reduced by approximately $47 \%$ at $64 \mu \mathrm{g} / \mathrm{ml}$ (Figure 3B), whereas the biofilm was decreased by $80 \%$ at this concentration. This result suggests that the inhibition of biofilm formation is not absolutely dependent on the inhibition of the SrtA activity.

Another possible mechanism is that kaempferol represses the gene expression of some surface proteins. Since kaempferol specifically affects the attachment phase of biofilm formation, we selected genes associated with adhesion protein expression. The clumping factors ClfA and ClfB encoded by the genes clfA and $c l f B$ are the most important proteins for the binding of S. aureus to fibrinogen (Gowrishankar et al., 2016). In S. aureus, ClfA and ClfB are fibrinogen-binding proteins (Otto, 2004; Foster et al., 2014) that are up-regulated during the biofilm growth (Resch et al., 2005). In addition to fibrinogen-binding proteins, $S$. aureus has two fibronectin-binding proteins, FnBPA and $\mathrm{FnBPB}$, which are encoded by $f_{n} b A$ and $f_{n} b B$, respectively
(Jonsson et al., 1991). FnBPs are thought to promote biofilm formation using a self-association mechanism distinct from ligand binding, making them multifunctional in the $S$. aureus biofilm life cycle (Geoghegan et al., 2013; Herman-Bausier et al., 2015).

In $S$. aureus, SarA is a global regulator that is closely related to biofilm formation in vitro (Paharik and Horswill, 2016). Thus, the global regulatory gene sarA was examined in this study. The effect of kaempferol on the transcription level of adhesion-related genes was tested by qRT-PCR. As shown in Figure 5, the transcription levels of clfA, clfB, $f n b B, f n b A$, and sarA were reduced by kaempferol. SarA is required to form biofilm in S. aureus (Beenken et al., 2003; Zielinska et al., 2012) and can positively regulate $f n b A$ and $f n b B$ (Dunman et al., 2001). Moreover, the inactivation of SarA resulted in decreased production of fibronectin-binding protein and fibrinogen-binding protein (Arvidson and Tegmark, 2001). We infer from these results that kaempferol is likely to act on the expression of these genes and lead to the biofilm formation inhibited.

In addition, by TEM, we observed many fibrous protrusions around the wild-type strain (Figures 4A,E). After treatment with proteinase $K$, the biofilm dispersed, and the fibrous protrusions disappeared (Figures $4 \mathbf{B}, \mathbf{F}$ ). Thus, we speculated that the fibrous protrusions were important for biofilm formation and consisted mainly of proteins. Moreover, by confocal laser microscopy, we observed significant green fluorescence around the wild-type strain (Figure 4I) because of the proteins surrounding the bacteria. We observed a reduction in green fluorescence (Figure 4J) after treatment with kaempferol $(64 \mu \mathrm{g} / \mathrm{ml})$. According to this result, we further inferred that the fibrous protrusions mainly consisted of proteins and that kaempferol could reduce the production of these proteins. Moreover, the surface of the $\Delta$ SrtA strain is also smooth (Figures 4C,G), and this strain has no ability to form biofilm (Figure 3A), indicating that surface proteins mediated by SrtA 
may be the major components of the fibrous protrusions and are important for biofilm formation. We observed a significant reduction in fibrous protrusions on the surface of bacteria treated with $64 \mu \mathrm{g} / \mathrm{ml} \mathrm{kaempferol} \mathrm{(Figures} \mathrm{4D,H).}$ According to these results, we conclude that kaempferol inhibits biofilm formation by reducing $S$. aureus surface proteins.

In a word, kaempferol can prevent $S$. aureus biofilm formation effectively even at sub-inhibitory concentrations. It is possible to be used on medical devices as anti-biofilm coatings to prevent infections. Therefore, we believe that kaempferol is a potential compound with a novel mechanism of biofilm inhibition, which could provide a lead structure for the development of future anti-biofilm drugs.

\section{REFERENCES}

Aaron, S. D., Ferris, W., Ramotar, K., Vandemheen, K., Chan, F., and Saginur, R. (2002). Single and combination antibiotic susceptibilities of planktonic, adherent, and biofilm-grown Pseudomonas aeruginosa isolates cultured from sputa of adults with cystic fibrosis. J. Clin. Microbiol. 40, 4172-4179. doi: 10.1128/JCM.40.11.4172-4179.2002

Abouelhassan, Y., Garrison, A. T., Burch, G. M., Wong, W., Norwood, V. M. IV., and Huigens, R. W. III. (2014). Discovery of quinoline small molecules with potent dispersal activity against methicillin-resistant Staphylococcus aureus and Staphylococcus epidermidis biofilms using a scaffold hopping strategy. Bioorg. Med. Chem. Lett. 24, 5076-5080. doi: 10.1016/j.bmcl.2014.09.009

Aendekerk, S., Diggle, S. P., Song, Z., Hoiby, N., Cornelis, P., Williams, P., et al. (2005). The MexGHI-OpmD multidrug efflux pump controls growth, antibiotic susceptibility and virulence in Pseudomonas aeruginosa via 4-quinolone-dependent cell-to-cell communication. Microbiology 151, 1113-1125. doi: 10.1099/mic.0.27631-0

Anderson, G. G., and O'Toole, G. A. (2008). "Innate and induced resistance mechanisms of bacterial biofilms," in Bacterial Biofilms, ed T. Romeo (Berlin; Heidelberg: Springer), 85-105. doi: 10.1007/978-3-540-75418-3_5

Arvidson, S., and Tegmark, K. (2001). Regulation of virulence determinants in Staphylococcus aureus. Int. J. Med. Microbiol. 291, 159-170. doi: 10.1078/1438-4221-00112

Beenken, K. E., Blevins, J. S., and Smeltzer, M. S. (2003). Mutation of sarA in Staphylococcus aureus limits biofilm formation. Infect. Immun. 71, 4206-4211. doi: 10.1128/IAI.71.7.4206-4211.2003

Bi, C., Dong, X., Zhong, X., Cai, H., Wang, D., and Wang, L. (2016). Acacetin protects mice from Staphylococcus aureus bloodstream infection by inhibiting the activity of sortase A. Molecules 21:E1285. doi: 10.3390/molecules21101285

Bjarnsholt, T., Jensen, P. O., Burmolle, M., Hentzer, M., Haagensen, J. A. J., Hougen, H. P., et al. (2005). Pseudomonas aeruginosa tolerance to tobramycin, hydrogen peroxide and polymorphonuclear leukocytes is quorum-sensing dependent. Microbiology 151, 373-383. doi: 10.1099/mic.0.27463-0

Boles, B. R., and Horswill, A. R. (2011). Staphylococcal biofilm disassembly. Trends Microbiol. 19, 449-455. doi: 10.1016/j.tim.2011.06.004

Brackman, G., and Coenye, T. (2015). Quorum sensing inhibitors as anti-biofilm agents. Curr. Pharm. Des. 21, 5-11. doi: 10.2174/1381612820666140905114627

Brown, A. R., Ettefagh, K. A., Todd, D., Cole, P. S., Egan, J. M., Foil, D. H., et al. (2015). A mass spectrometry-based assay for improved quantitative measurements of efflux pump inhibition. PLoS ONE 10:e124814. doi: 10.1371/journal.pone.0124814

Cascioferro, S., Totsika, M., and Schillaci, D. (2014). Sortase A: an ideal target for anti-virulence drug development. Microb. Pathog. 77, 105-112. doi: 10.1016/j.micpath.2014.10.007

Chen, F., Liu, B., Wang, D., Wang, L., Deng, X., Bi, C., et al. (2014). Role of sortase a in the pathogenesis of Staphylococcus aureus-induced mastitis in mice. FEMS Microbiol. Lett. 351, 95-103. doi: 10.1111/1574-6968.12354

\section{AUTHOR CONTRIBUTIONS}

Conceived and designed the experiments: DMi, DW, FC, LW, and TW. Performed the experiments: DMi, FC, DMu, JC, BL, and LZ. Analyzed the data: DMi, FC, LW, HX, XD and XZ. Wrote the paper: DMi, DW, and LW. All authors participated in discussion about the results and the manuscript.

\section{ACKNOWLEDGMENTS}

This work was supported by The National Key Technology R\&D Program (No. 2016YFD05013) and the China Education Department of Jilin province science and technology research project of the "13th Five-Year" ([2016] No. 194).

Cho, H. S., Lee, J.-H., Cho, M. H., and Lee, J. (2015). Red wines and flavonoids diminish Staphylococcus aureus virulence with anti-biofilm and anti-hemolytic activities. Biofouling 31, 1-11. doi: 10.1080/08927014.2014. 991319

Chu, M., Zhang, M.-B., Liu, Y.-C., Kang, J.-R., Chu, Z.-Y., Yin, K.-L., et al. (2016). Role of berberine in the treatment of methicillin-resistant Staphylococcus aureus infections. Sci. Rep. 6:24748. doi: 10.1038/srep24748

Chung, P. Y., and Toh, Y. S. (2014). Anti-biofilm agents: recent breakthrough against multi-drug resistant Staphylococcus aureus. Pathog. Dis. 70, 231-239. doi: 10.1111/2049-632X.12141

Costerton, J. W., Stewart, P. S., and Greenberg, E. P. (1999). Bacterial biofilms: a common cause of persistent infections. Science 284, 1318-1322. doi: 10.1126/science.284.5418.1318

Dunman, P. M., Murphy, E., Haney, S., Palacios, D., Tucker-Kellogg, G., Wu, S., et al. (2001). Transcription profiling-based identification of Staphylococcus aureus genes regulated by the agr and/or sarA loci. J. Bacteriol. 183, 7341-7353. doi: 10.1128/JB.183.24.7341-7353.2001

Foster, T. J., Geoghegan, J. A., Ganesh, V. K., and Hook, M. (2014). Adhesion, invasion and evasion: the many functions of the surface proteins of Staphylococcus aureus. Nat. Rev. Microbiol. 12, 49-62. doi: 10.1038/nrmicro3161

Geoghegan, J. A., Monk, I. R., O’Gara, J. P., and Foster, T. J. (2013). Subdomains N2N3 of fibronectin binding protein a mediate Staphylococcus aureus biofilm formation and adherence to fibrinogen using distinct mechanisms. J. Bacteriol. 195, 2675-2683. doi: 10.1128/JB.02128-12

Götz, F. (2002). Staphylococcus and biofilms. Mol. Microbiol. 43, 1367-1378. doi: 10.1046/j.1365-2958.2002.02827.x

Gowrishankar, S., Kamaladevi, A., Balamurugan, K., and Pandian, S. K. (2016). In vitro and in vivo biofilm characterization of methicillin-resistant staphylococcus aureus from patients associated with pharyngitis infection. Biomed Res. Int. 2016:1289157. doi: 10.1155/2016/1289157

Harmsen, M., Lappann, M., Knøchel, S., and Molin, S. (2010). Role of extracellular DNA during biofilm formation by listeria monocytogenes. Appl. Environ. Microbiol. 76, 2271-2279. doi: 10.1128/AEM.02361-09

Herman-Bausier, P., El-Kirat-Chatel, S., Foster, T. J., Geoghegan, J. A., and Dufrene, Y. F. (2015). Staphylococcus aureus fibronectin-binding protein a mediates cell-cell adhesion through low-affinity homophilic bonds. mBio 6:e0413-15. doi: 10.1128/mBio.00413-15

Hochbaum, A. I., Kolodkin-Gal, I., Foulston, L., Kolter, R., Aizenberg, J., and Losick, R. (2011). Inhibitory effects of D-amino acids on Staphylococcus aureus biofilm development. J. Bacteriol. 193, 5616-5622. doi: 10.1128/JB. 05534-11

Hoyle, B. D., and Costerton, J. W. (1991). "Bacterial resistance to antibiotics: the role of biofilms," in Progress in Drug Research/Fortschritte der Arzneimittelforschung/Progrès des Recherches Pharmaceutiques, ed E. Jucker (Basel: Birkhäuser Basel), 91-105. doi: 10.1007/978-3-03487139-6_2 
Huang, Y. H., Huang, C. C., Chen, C. C., Yang, K. J., and Huang, C. Y. (2015). Inhibition of Staphylococcus aureus PriA helicase by flavonol kaempferol. Protein J. 34, 169-172. doi: 10.1007/s10930-015-9609-y

Itoh, Y., Wang, X., Hinnebusch, B. J., Preston, J. F. III., and Romeo, T. (2005). Depolymerization of $\beta-1,6-\mathrm{N}$-acetyl-D-glucosamine disrupts the integrity of diverse bacterial biofilms. J. Bacteriol. 187, 382-387. doi: 10.1128/JB.187.1.382-387.2005

Jia, M., Chen, Z., Guo, Y., Chen, X., and Zhao, X. (2017). Efficacy of silk fibroinnano silver against Staphylococcus aureus biofilms in a rabbit model of sinusitis. Int. J. Nanomed. 12, 2933-2939. doi: 10.2147/IJN.S130160

Jonsson, K., Signas, C., Muller, H. P., and Lindberg, M. (1991). Two different genes encode fibronectin binding proteins in Staphylococcus aureus. The complete nucleotide sequence and characterization of the second gene. Eur. J. Biochem. 202, 1041-1048. doi: 10.1111/j.1432-1033.1991.tb16468.x

Kelly, D., McAuliffe, O., Ross, R. P., and Coffey, A. (2012). Prevention of Staphylococcus aureus biofilm formation and reduction in established biofilm density using a combination of phage $\mathrm{K}$ and modified derivatives. Lett. Appl. Microbiol. 54, 286-291. doi: 10.1111/j.1472-765X.2012. 03205.x

Lee, J.-H., Kim, Y.-G., Ryu, S. Y., Cho, M. H., and Lee, J. (2014). Ginkgolic acids and Ginkgo biloba extract inhibit Escherichia coli O157:H7 and Staphylococcus aureus biofilm formation. Int. J. Food Microbiol. 174, 47-55. doi: 10.1016/j.ijfoodmicro.2013.12.030

Lee, J.-H., Kim, Y.-G., Yong Ryu, S., and Lee, J. (2016). Calcium-chelating alizarin and other anthraquinones inhibit biofilm formation and the hemolytic activity of Staphylococcus aureus. Sci. Rep. 6:19267. doi: 10.1038/srep19267

Lee, J.-H., Park, J.-H., Cho, H. S., Joo, S. W., Cho, M. H., and Lee, J. (2013). Antibiofilm activities of quercetin and tannic acid against Staphylococcus aureus. Biofouling 29, 491-499. doi: 10.1080/08927014.2013.788692

Li, J. W.-H., and Vederas, J. C. (2009). Drug discovery and natural products: end of an era or an endless frontier? Science 325, 161-165. doi: $10.1126 /$ science. 1168243

Livak, K. J., and Schmittgen, T. D. (2001). Analysis of relative gene expression data using real-time quantitative PCR and the $2^{-\Delta \Delta C} \mathrm{~T}$ method. Methods 25, 402-408. doi: 10.1006/meth.2001.1262

Lowy, F. D. (1998). Staphylococcus aureus infections. N. Engl. J. Med. 339, 520-532. doi: 10.1056/NEJM199808203390806

Mah, T. F., and O'Toole, G. A. (2001). Mechanisms of biofilm resistance to antimicrobial agents. Trends Microbiol. 9, 34-39. doi: 10.1016/S0966-842X(00) 01913-2

Massey, R. C., Dissanayeke, S. R., Cameron, B., Ferguson, D., Foster, T. J., and Peacock, S. J. (2002). Functional blocking of Staphylococcus aureus adhesins following growth in ex vivo media. Infect. Immun. 70, 5339-5345. doi: 10.1128/IAI.70.10.5339-5345.2002

Mazmanian, S. K., Liu, G., Ton-That, H., and Schneewind, O. (1999). Staphylococcus aureus sortase, an enzyme that anchors surface proteins to the cell wall. Science 285, 760-763. doi: 10.1126/science.285.5428.760

Mazmanian, S. K., Ton-That, H., Su, K., and Schneewind, O. (2002). An iron-regulated sortase anchors a class of surface protein during Staphylococcus aureus pathogenesis. Proc. Natl. Acad. Sci. U.S.A. 99, 2293-2298. doi: $10.1073 /$ pnas. 032523999

McDevitt, D., Nanavaty, T., House-Pompeo, K., Bell, E., Turner, N., McIntire, L., et al. (1997). Characterization of the interaction between the Staphylococcus aureus clumping factor (ClfA) and fibrinogen. Eur. J. Biochem. 247, 416-424. doi: 10.1111/j.1432-1033.1997.00416.x

Mistry, H., Sharma, P., Mahato, S., Saravanan, R., Kumar, P. A., and Bhandari, V. (2016). Prevalence and characterization of oxacillin susceptible meca-positive clinical isolates of staphylococcus aureus causing bovine mastitis in India. PLoS ONE 11:e0162256. doi: 10.1371/journal.pone.0162256

Mogosanu, G. D., Grumezescu, A. M., Huang, K.-S., Bejenaru, L. E., and Bejenaru, C. (2015). Prevention of microbial communities: novel approaches based natural products. Curr. Pharm. Biotechnol. 16, 94-111. doi: 10.2174/138920101602150112145916

Ní Eidhin, D., Perkins, S., Francois, P., Vaudaux, P., Höök, M., and Foster, T. J. (1998). Clumping factor B (ClfB), a new surface-located fibrinogenbinding adhesin of Staphylococcus aureus. Mol. Microbiol. 30, 245-257. doi: $10.1046 / j .1365-2958.1998 .01050 . x$
O'Gara, J. P., and Humphreys, H. (2001). Staphylococcus epidermidis biofilms: importance and implications. J. Med. Microbiol. 50, 582-587. doi: 10.1099/0022-1317-50-7-582

Otto, M. (2004). Virulence factors of the coagulase-negative staphylococci. Front. Biosci. 9, 841-863. doi: 10.2741/1295

Otto, M. (2008). Staphylococcal biofilms. Curr. Top. Microbiol. Immunol. 322, 207-228. doi: 10.1007/978-3-540-75418-3_10

Otto, M. (2013). Staphylococcal infections: mechanisms of biofilm maturation and detachment as critical determinants of pathogenicity. Annu. Rev. Med. 64, 175-188. doi: 10.1146/annurev-med-042711-140023

Otto, M. (2014). Physical stress and bacterial colonization. FEMS Microbiol. Rev. 38, 1250-1270. doi: 10.1111/1574-6976.12088

Paharik, A. E., and Horswill, A. R. (2016). The staphylococcal biofilm: adhesins, regulation, and host response. Microbiol. Spectr. 4, 1-27. doi: 10.1128/microbiolspec.VMBF-0022-2015

Parsek, M. R., and Singh, P. K. (2003). Bacterial biofilms: an emerging link to disease pathogenesis. Annu. Rev. Microbiol. 57, 677-701. doi: 10.1146/annurev.micro.57.030502.090720

Patti, J. M., Allen, B. L., McGavin, M. J., and Hook, M. (1994). MSCRAMMmediated adherence of microorganisms to host tissues. Annu. Rev. Microbiol. 48, 585-617. doi: 10.1146/annurev.mi.48.100194.003101

Payne, D. E., Martin, N. R., Parzych, K. R., Rickard, A. H., Underwood, A., and Boles, B. R. (2013). Tannic acid inhibits Staphylococcus aureus surface colonization in an IsaA-dependent manner. Infect. Immun. 81, 496-504. doi: 10.1128/IAI.00877-12

Pletzer, D., and Hancock, R. E. W. (2016). Antibiofilm peptides: potential as broad-spectrum agents. J. Bacteriol. 198, 2572-2578. doi: 10.1128/JB.00017-16

Qiu, J., Niu, X., Dong, J., Wang, D., Wang, J., Li, H., et al. (2012). Baicalin protects mice from Staphylococcus aureus pneumonia via inhibition of the cytolytic activity of alpha-hemolysin. J. Infect. Dis. 206, 292-301. doi: 10.1093/infdis/jis336

Quave, C. L., Estevez-Carmona, M., Compadre, C. M., Hobby, G., Hendrickson, H., Beenken, K. E., et al. (2012). Ellagic acid derivatives from Rubus ulmifolius inhibit Staphylococcus aureus biofilm formation and improve response to antibiotics. PLOS ONE 7:e28737. doi: 10.1371/journal.pone. 0028737

Rendueles, O., Kaplan, J. B., and Ghigo, J.-M. (2013). Antibiofilm polysaccharides. Environ. Microbiol. 15, 334-346. doi: 10.1111/j.1462-2920.2012. 02810.x

Resch, A., Rosenstein, R., Nerz, C., and Gotz, F. (2005). Differential gene expression profiling of Staphylococcus aureus cultivated under biofilm and planktonic conditions. Appl. Environ. Microbiol. 71, 2663-2676. doi: 10.1128/AEM.71.5.2663-2676.2005

Rogers, S. A., Huigens, R. W. III., Cavanagh, J., and Melander, C. (2010). Synergistic effects between conventional antibiotics and 2-aminoimidazolederived antibiofilm agents. Antimicrob. Agents Chemother. 54, 2112-2118. doi: 10.1128/AAC.01418-09

Romling, U., and Balsalobre, C. (2012). Biofilm infections, their resilience to therapy and innovative treatment strategies. J. Intern. Med. 272, 541-561. doi: 10.1111/joim.12004

Ross, J. A., and Kasum, C. M. (2002). Dietary flavonoids: bioavailability, metabolic effects, and safety. Annu. Rev. Nutr. 22, 19-34. doi: 10.1146/annurev.nutr.22.111401.144957

Singhal, D., Foreman, A., Bardy, J. J., and Wormald, P. J. (2011). Staphylococcus aureus biofilms: nemesis of endoscopic sinus surgery. Laryngoscope 121, 1578-1583. doi: 10.1002/lary.21805

Ton-That, H., Liu, G., Mazmanian, S. K., Faull, K. F., and Schneewind, O. (1999). Purification and characterization of sortase, the transpeptidase that cleaves surface proteins of Staphylococcus aureus at the LPXTG motif. Proc. Natl. Acad. Sci. U.S.A. 96, 12424-12429. doi: 10.1073/pnas.96.22.12424

Von Eiff, C., Peters, G., and Heilmann, C. (2002). Pathogenesis of infections due to coagulase-negative staphylococci. Lancet Infect. Dis. 2, 677-685. doi: 10.1016/S1473-3099(02)00438-3

Wang, D., Jin, Q., Xiang, H., Wang, W., Guo, N., Zhang, K., et al. (2011). Transcriptional and functional analysis of the effects of magnolol: inhibition of autolysis and biofilms in Staphylococcus aureus. PLoS ONE 6:e26833. doi: 10.1371/journal.pone.0026833 
Wang, J., Qiu, J., Tan, W., Zhang, Y., Wang, H., Zhou, X., et al. (2015). Fisetin inhibits Listeria monocytogenes virulence by interfering with the oligomerization of listeriolysin O. J. Infect. Dis. 211, 1376-1387. doi: 10.1093/infdis/jiu520

Wang, L., Bi, C., Cai, H., Liu, B., Zhong, X., Deng, X., et al. (2015). The therapeutic effect of chlorogenic acid against Staphylococcus aureus infection through sortase a inhibition. Front. Microbiol. 6:1031. doi: 10.3389/fmicb.2015. 01031

Yadav, M. K., Chae, S.-W., Im, G. J., Chung, J.-W., and Song, J.-J. (2015). Eugenol: a phyto-compound effective against methicillin-resistant and methicillinsensitive Staphylococcus aureus clinical strain biofilms. PLoS ONE 10:e119564. doi: 10.1371/journal.pone.0119564

Zapotoczna, M., McCarthy, H., Rudkin, J. K., O’Gara, J. P., and O’Neill, E. (2015). An essential role for coagulase in Staphylococcus aureus biofilm development reveals new therapeutic possibilities for device-related infections. J. Infect. Dis. 212, 1883-1893. doi: 10.1093/infdis/jiv319
Zielinska, A. K., Beenken, K. E., Mrak, L. N., Spencer, H. J., Post, G. R., Skinner, R. A., et al. (2012). sarA-mediated repression of protease production plays a key role in the pathogenesis of Staphylococcus aureus USA300 isolates. Mol. Microbiol. 86, 1183-1196. doi: 10.1111/mmi.12048

Conflict of Interest Statement: The authors declare that the research was conducted in the absence of any commercial or financial relationships that could be construed as a potential conflict of interest.

Copyright (C) 2017 Ming, Wang, Cao, Xiang, Mu, Cao, Li, Zhong, Dong, Zhong, Wang and Wang. This is an open-access article distributed under the terms of the Creative Commons Attribution License (CC BY). The use, distribution or reproduction in other forums is permitted, provided the original author(s) or licensor are credited and that the original publication in this journal is cited, in accordance with accepted academic practice. No use, distribution or reproduction is permitted which does not comply with these terms. 